\title{
Retrofitting of an Existing Condensate Recovery Plant to Maximize Natural Gas Liquids Production
}

\author{
Mohamed Magdy El-Eishy ${ }^{1,}$, , Galal Mohamed Abdelalim ${ }^{1}$, Tarek Mohamed Aboul-Fotouh ${ }^{2}$ \\ ${ }^{1}$ Chemical Engineering and Petroleum Refining Department, Suez University, Suez, Egypt \\ ${ }^{2}$ Mining and Petroleum Engineering Department, Al-Azhar University, Cairo, Egypt
}

Email address:

mohamed.alaeshy@yahoo.com (M. M. El-Eishy),drgalal@hotmail.com (G. M. Abdelalim), aboulfotouh@azhar.edu.eg (T. M. Aboul-Fotouh)

*Corresponding author

\section{To cite this article:}

Mohamed Magdy El-Eishy, Galal Mohamed Abdelalim, Tarek Mohamed Aboul-Fotouh. Retrofitting of an Existing Condensate Recovery Plant to Maximize Natural Gas Liquids Production. International Journal of Oil, Gas and Coal Engineering. Vol. 6, No. 1, 2018, pp. 8-17. doi: $10.11648 /$ j.ogce. 20180601.12

Received: October 3, 2017; Accepted: October 23, 2017; Published: January 15, 2018

\begin{abstract}
Nowadays, gas processing for NGLs (Natural Gas Liquids) and LPG (Liquefied Petroleum Gas) recovery has gained a great interest due to the increase of the market demand as well as the higher prices of these products. Based on sales gas calorific value from ABU-SANNAN Condensate Recovery Plant (General Petroleum Company-Egypt) and by close monitoring of NGLs content in feed and sales gas, it is clear that there is a valuable amount of NGLs leave with sales gas without recovery. NGLs have significantly greater value as separated products than as part of the gas stream, so General Petroleum Company could seek ways and means to maximize NGLs recovery. The current research work proposes a possible modification of ABU-SANNAN Condensate Recovery Plant to produce liquefied petroleum gas (LPG) from natural gas liquids (NGLs), instead of producing lighter hydrocarbon gases during the stabilization process, in addition to the current condensate and sales gas products. The new LPG recovery unit will comprises of: Molecular Sieve based-dehydration unit, Turbo-Expander unit, Cold Box heat exchanger, DE-ETHANIZER system, DE-ETHANIZER Overhead compressor, DEBUTANIZER system, and two LPG storage bullets. New process equipment selection, sizing and rating will be performed by using Aspen HYSYS simulation program V8.8. The results show that the retrofitted plant can produce 87 Tons/Day of LPG. The produced LPG can participate to solve the LPG shortage problem in Egypt. The economic evaluation for the Retrofitted Plant is conducted by using Aspen Capital Cost Estimator V8.8, to ensure rapid return of investment and good profitability over the expected lifetime. It is remarkable that the Retrofitted plant has a great value from the economic point of view as the total capital investment will be paid back within two years, so the Retrofitted plant will achieve a high and rapid return on investment (ROI). The efforts done in this work are helpful and can be applied for plants in operation as well as the plants under design for increasing their profits.
\end{abstract}

Keywords: Retrofitting, Condensate Stabilization, Simulation, LPG

\section{Introduction}

Natural gas is a combustible mixture of hydrocarbon gases and other impurities [1-5]. The natural gas industry was started in the beginning of the twentieth century in the United States. This industry produces high quality fuel as it considered one of the cleanest fuel sources all over the world. Besides that, many valuable petroleum chemicals produced from this industry. Raw natural gas is found in deep reservoirs underground. This raw natural gas occurs either in association with crude oil as it named associated gas or dry gas without crude oil which named non-associated gases. Although, this dry gas may contain large amount of NGLs components.

Natural gas processing and the removal various components from it tend to involve the most complex and 
expensive processes [6-8]. All of $\mathrm{H}_{2} \mathrm{~S}$, most of water vapor, $\mathrm{CO}_{2}$, and $\mathrm{N}_{2}$ must be removed firstly. The separation of hydrocarbons, known as NGL $\left(\mathrm{C}_{2}\right.$ plus $)$, is carried out next producing methane as the sole product commercially marketed as natural gas.

Process simulation has become an essential tool for operators and engineering firms in the oil \& gas industry [9, 10]. Simulators can better support process design, debottlenecking and optimization when used to their full potential. Aspen HYSYS is the market-leading process modeling and simulation solution with a proven track record of providing substantial economic benefits throughout the process engineering lifecycle. It brings the power of process simulation and optimization to the engineering desktop, and delivers a unique combination of modeling technology and ease of use.

There are two situations that can be encountered in process design [11-13]. The first is in the design of new plant or grass root design (Green plant). In the second, the design is carried out to modify an existing plant in retrofit or revamp (Brown plant). The motivation to retrofit an existing plant could be, for example, to increases capacity, allow for different feed or product specifications, reduce operating costs, improve safety or reduce environmental emissions. Retrofitting the existing plants to a more efficient process can provide the following benefits: Higher process efficiency, reduces the energy consumption per unit of gas processed and allows increased plant throughput with the same gas compression power that reducing the fixed costs per unit of gas processed. Increased plant throughput is translated into greater product sales and revenue. Liquid recovery efficiency can also be increased, further raising product sales and revenue.

The economic evaluation is an important and integral part of the overall feasibility study of the project [14, 15]. An acceptable process plant design must present a process that is capable of operating under economical conditions. Since net profit equals total income minus all expenses, it is essential for process engineer to be aware of the types of costs involved in sales product recovery processes.

\section{ABU-SANNAN Condensate Stabilization Unit Process Description}

The ABU-SANNAN condensate recovery plant located about $300 \mathrm{~km}$ west of Cairo in the Western Desert of Egypt [16]. The purpose of the Abu-Sannan processing plant is to utilize the natural gas available from existing natural gas wells in the area and high pressure associated gases from the sisters companies. The plant is designed to process 85 MMSCFD of high pressure gas and about 3000 BBLs condensate. The processed gas from the plant is joins a much larger gas stream in the BAPETCO (BED-3) AMERYIA trunk line flowing to Alexandria.

Normally high pressure gas is received in the Slug Cather vessels. Here the liquid which is entrained in the gas or accumulates in the receiving pipeline is separated and pressured out to the high pressure flash drum. The overhead gas from the Slug Cather is then cooled and chilled, and additional condensate is knocked out in the Low Temperature Separator (LTS). The liquids from LTS go through heat exchanger, combined with the condensate from Slug Cather and are sent to the stabilizer section. Gases from stabilizer, the feed drum and the stabilizer overhead are combined and compressed in the overhead compressor. The discharge is then added to the lean gases which are further compressed in the booster compressor to the required residue gas pressure of the pipeline, the block diagram for the main unit operations in the existing gas plant is shown in Figure 1.

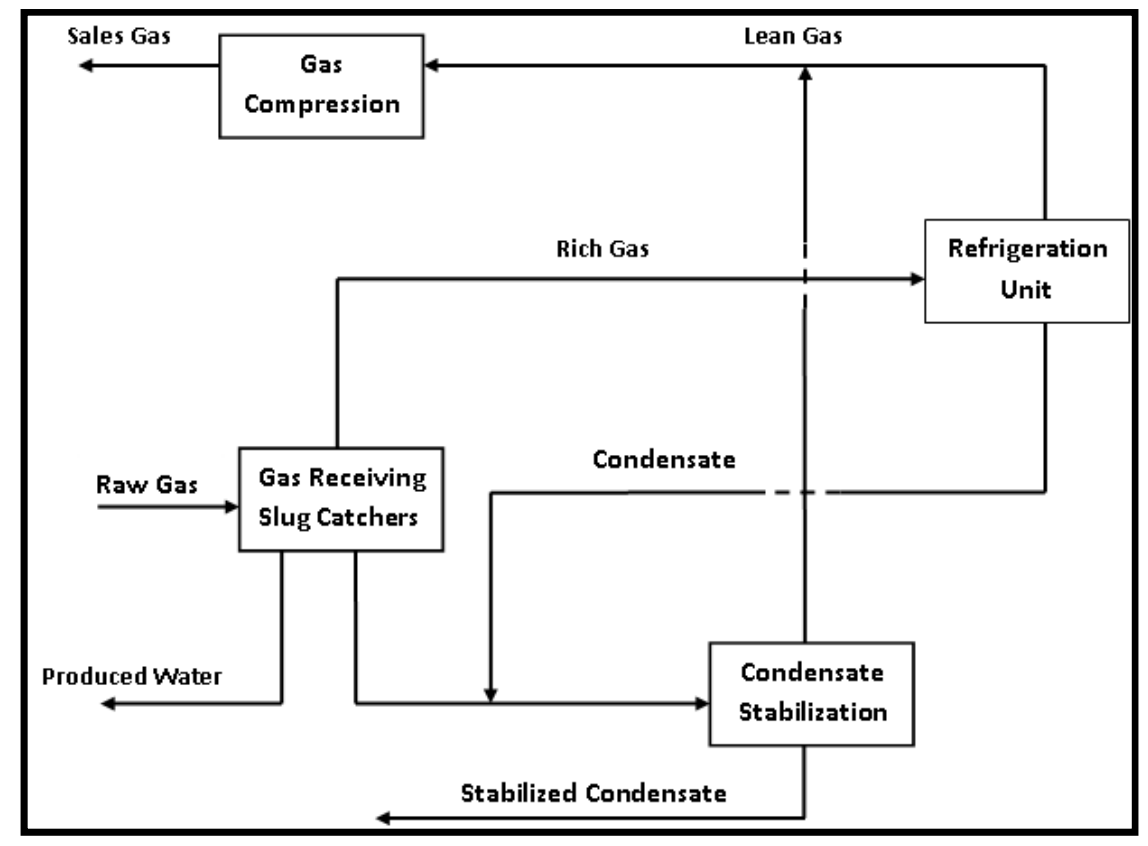

Figure 1. Block diagram for the existing condensate recovery plant. 


\section{Research Methodology}

The plan of this study is constructed as in the following steps:

\subsection{Data Extraction}

Where Inlet feed gas and feed liquid (condensate) samples were taken from the plant to be analyzed in the General Petroleum Company laboratory (Table 1). The actual operating conditions of the existing plant were obtained from daily plant operating conditions log sheets (Table 2 ).

Table 1. Laboratory results for plant feeds compositional analyses.

\begin{tabular}{lll}
\hline \multirow{2}{*}{ Component } & Mole Fraction & \\
\cline { 2 - 3 } & Feed Gas & Feed Condensate \\
\hline Methane & 0.8153 & 0.2056 \\
Ethane & 0.0913 & 0.0831 \\
Propane & 0.044 & 0.1008 \\
i-Butane & 0.0089 & 0.0397 \\
n-Butane & 0.0126 & 0.0682 \\
i-Pentane & 0.0046 & 0.0448 \\
n-Pentane & 0.0036 & 0.0438 \\
Hexane Plus & 0.0026 & 0.4076 \\
Nitrogen & 0.0048 & 0.0008 \\
$\mathrm{CO}_{2}$ & 0.012 & 0.0054 \\
$\mathrm{H}_{2} \mathrm{O}$ & 0.0003 & 0.0002 \\
\hline
\end{tabular}

Table 2. Actual plant operating conditions.

\begin{tabular}{lll}
\hline PROCESS VARIABLE & UNIT & VALUE \\
\hline Plant feed pressure & $\mathrm{kg} / \mathrm{cm}^{2}$ & 40 \\
Plant feed temperature & ${ }^{\circ} \mathrm{C}$ & 39 \\
$\begin{array}{l}\text { Molar flow rate } \\
\text { Stabilized Condensate }\end{array}$ & MMSCFD & 58.46 \\
Production Rate, & & \\
REID Vapor Pressure (RVP) & BBLs/Day & 561 \\
Sales Gas & psia & 12 \\
Flow Rate & MMSCFD & 57.38 \\
Gross Calorific Value & BTU/SCF & 1187 \\
\hline
\end{tabular}

\subsection{Constructing a Steady State Model for the Existing Condensate Recovery Plant}

Steady state model for the existing plant will be constructed by using ASPEN HYSYS V-8.8, as in the following steps: Building the Simulation Model for the Liquid Extraction Section (Figure 2), Mechanical Refrigeration Section (Figure 3), Condensate Stabilization Section (Figure 4), and Gas Compression Section (Figure 5).

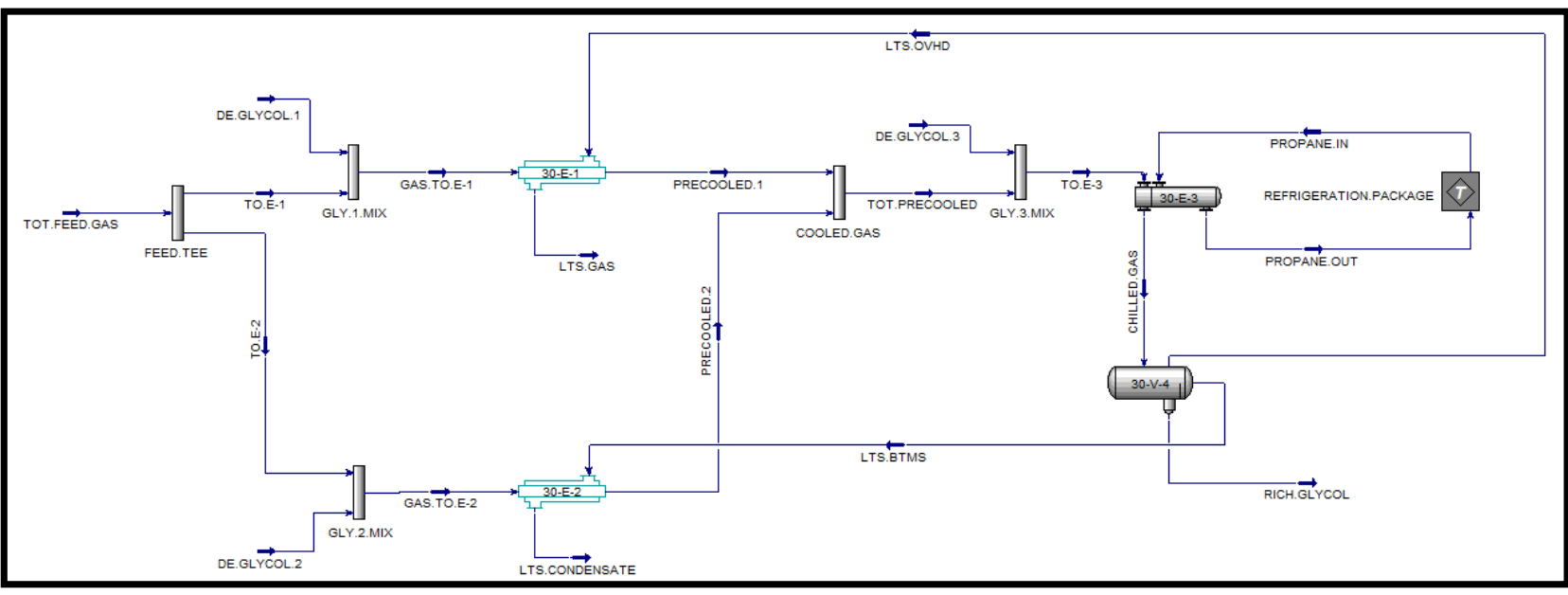

Figures 2. Constructing the Liquid Extraction Section by HYSYS.

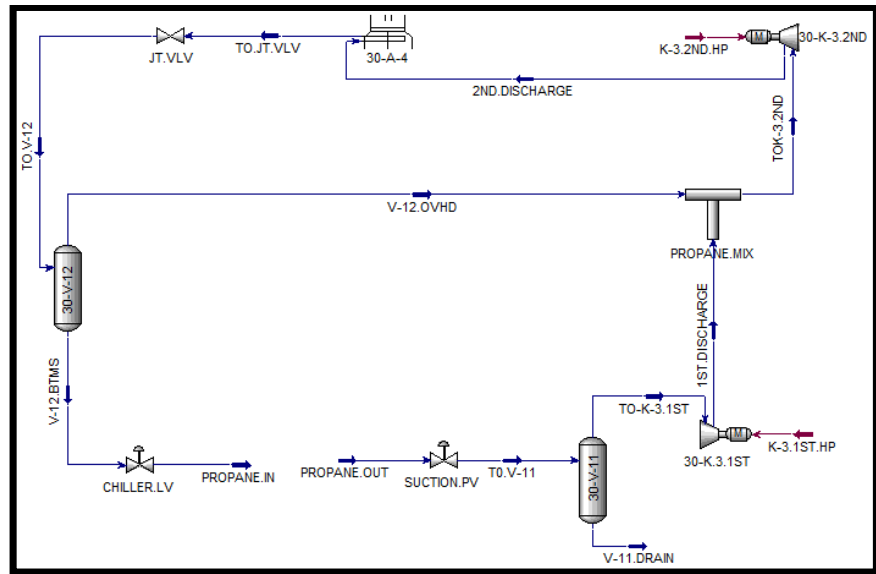

Figures 3. Constructing the Mechanical Refrigeration Section by HYSYS. 


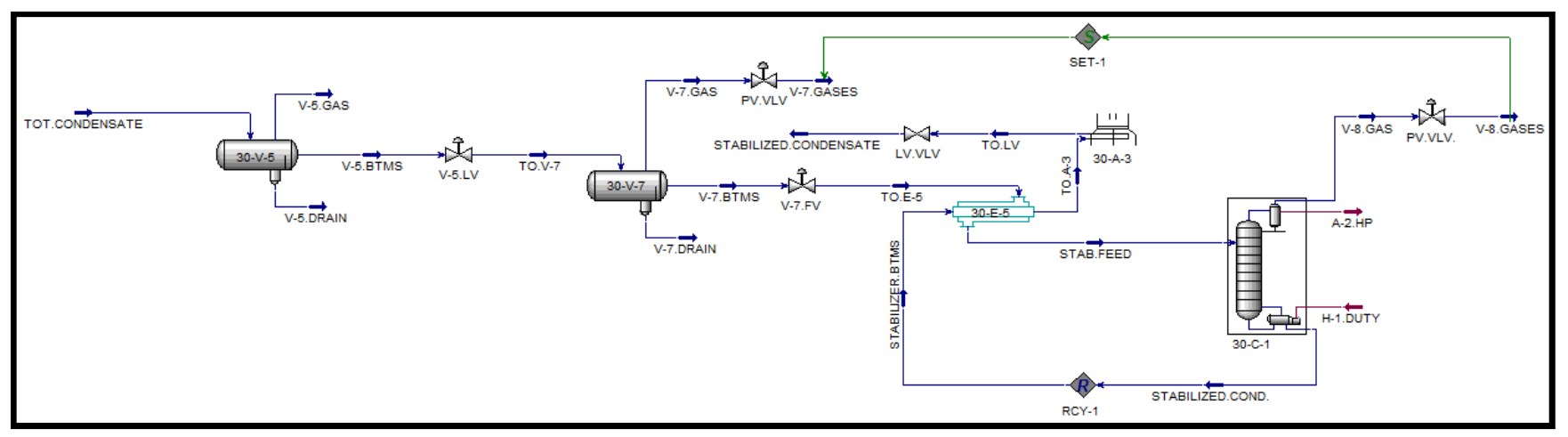

Figures 4. Constructing Condensate Stabilization Section by HYSYS.

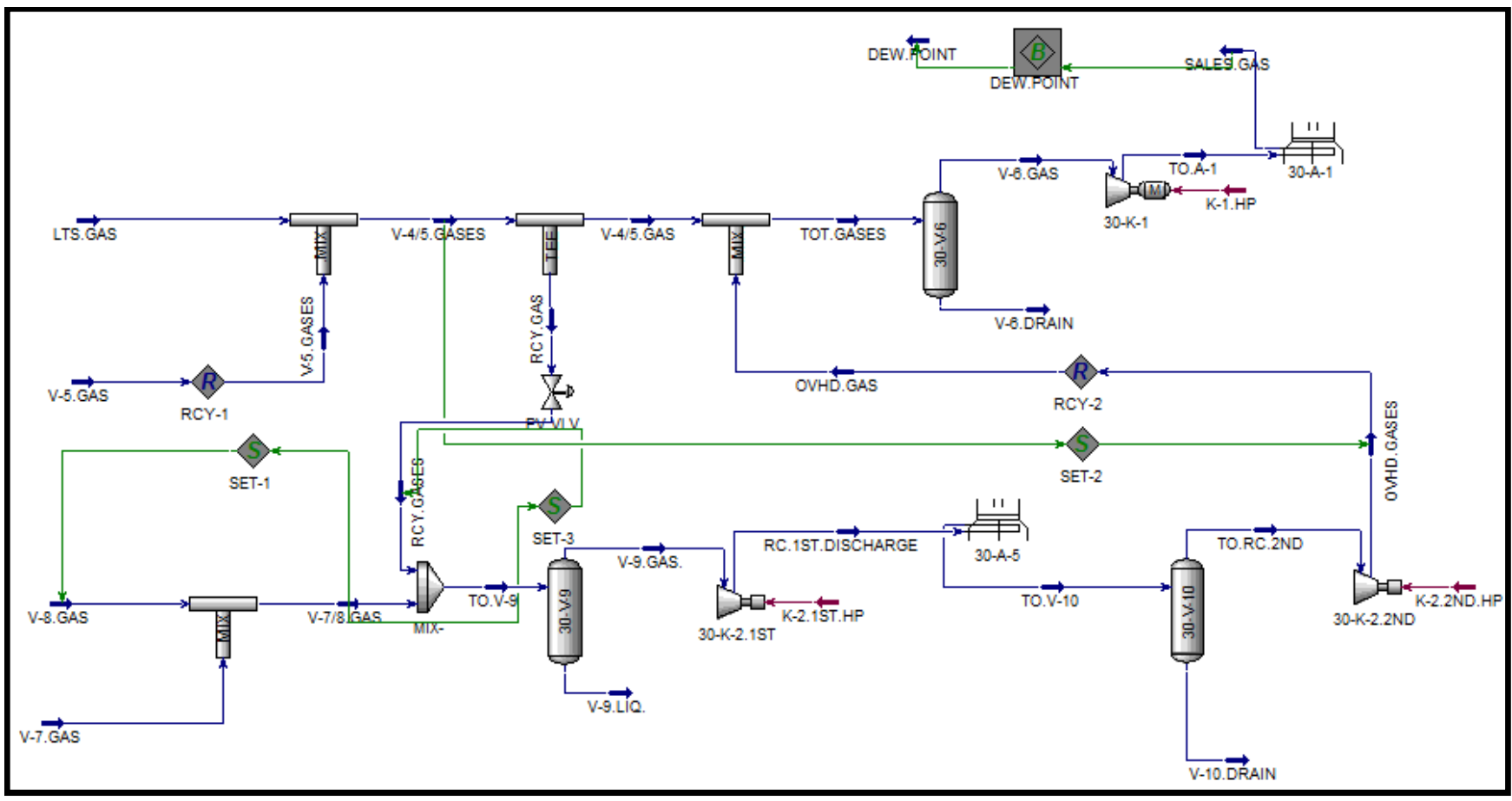

Figures 5. Constructing Sales Gas Compression Section by HYSYS.

\subsection{Model Validation}

Model Validation was conducted by testing against a period of five months for which production and operation conditions data were available. Statistical analyses of the real operating plant data and simulation results were conducted to check for any deviation between them.

\subsection{Retrofitted Plant Overview}

The processing facilities for the new retrofitted plant will be designed to recover LPG from NGLs. The chilled gas from the existing low temperature separator (LTS) will be sent to the new LPG recovery unit, where enters the Molecular Sieve based water dew point control unit. The dry gas flows from the Molecular Sieve unit will be entered the Cold Box Exchanger where it will be cooled down by the cold gas from Expander Discharge Vessel and cold condensate from Expander Suction Vessel. Due to this cooling, heavier hydrocarbons will be condensed and separated in Expander Suction Vessel. Then, gas from
Expander Suction Vessel is isentropically expanded through the Expander.

The natural gas and liquid hydrocarbons that condensed due to the Turbo-Expander's drop in temperature will be routed to the Expander Discharge Vessel for gas and liquid phase separation. The cold gas from Expander Discharge Vessel will be used in Cold Box Exchanger to pre-cool the inlet process gas. Then, this dry gas will further used in Gas/Gas exchanger to pre-cool the inlet raw gas. The dry gas is then recompressed in the Compressor side of the TurboExpander. After compression, the gas will be sent to Sales Gas Compressor and onward sales. Condensate from TurboExpander Suction Vessel, condensate from Turbo-Expander Discharge Vessel and condensate from LTS will be fed to the DE-ETHANIZER Column, to separate ethane from the heavier components.

The overhead product of the DE-ETHANIZER Column, ethane rich gas, will be re-compressed then sent to Sales Gas Compressor and onward sales. The bottom product of the DEETHANIZER Column will be sent to DE-BUTANIZER 
column to produce separately LPG and condensate. Condensate at the draw off side of the Re-boiler will be sent to
Condensate Stabilization Unit for further processing, Figure 6 illustrates the block diagram for the new retrofitted plant.

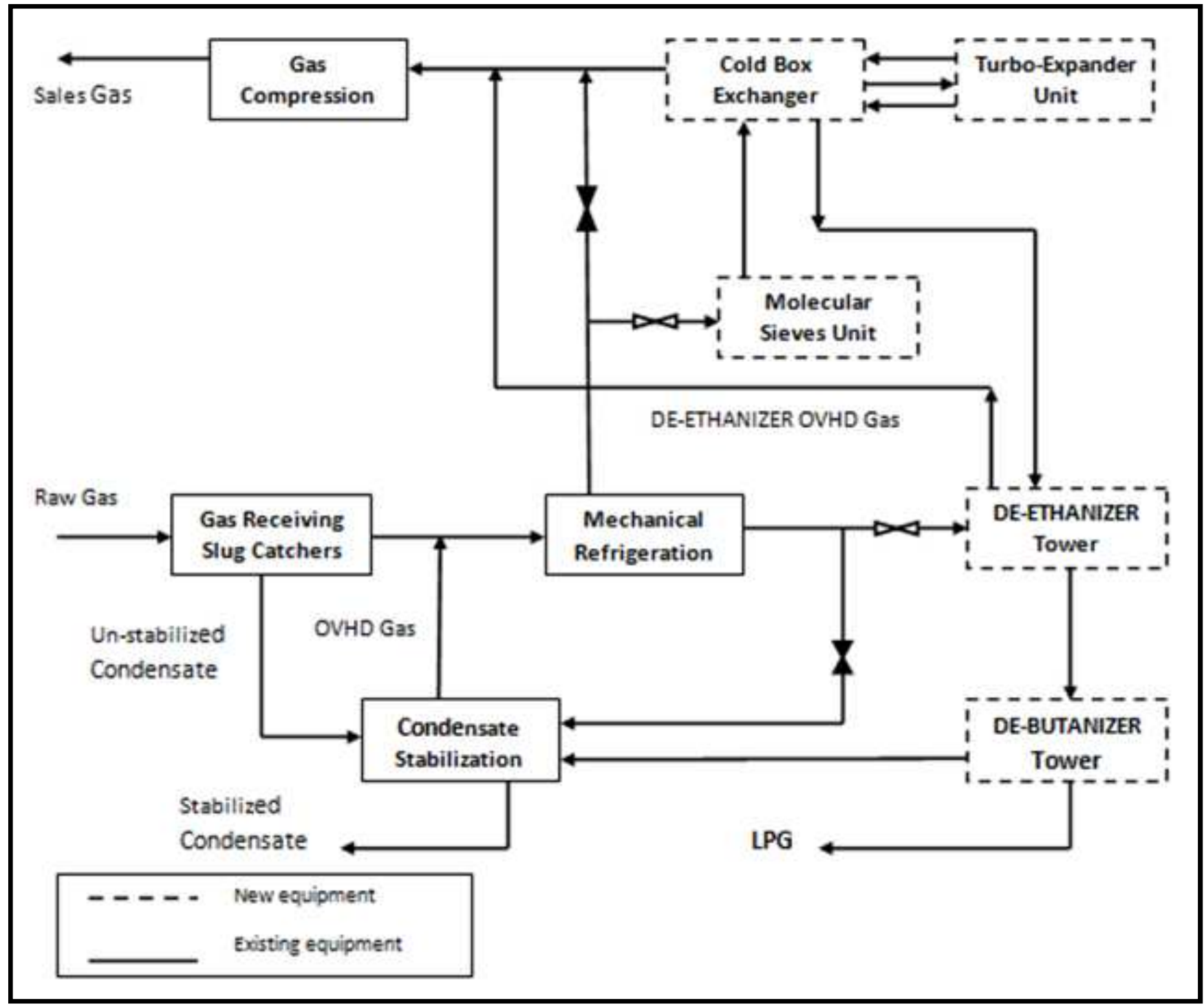

Figure 6. Block diagram for the new retrofitted plant.

\subsection{Modeling the Retrofitted Plant}

Steady state model for the Retrofitted Plant will be constructed by using ASPEN HYSYS V-8.8, as in the following steps: Installation of Molecular Sieve Unit, Hydrocarbon Dew Point Control Unit, DE-ETHANIZER SYSTEM, and DE-BUTANIZER SYSTEM.

\subsubsection{DE-ETHANIZER System Setting up}

This column is simulated as a distillation column. The performance of the proposed column is estimated by using the Shortcut Column model in HYSYS. Setting ethane as the light component in bottom product and its mole fraction is (0.0009) to ensure that most of heavier hydrocarbons will be separated in the bottom. Figure 7 illustrates the number of ideal trays, the optimal feed location, condenser duty and reboiler duty for the DE-ETHANIZER column obtained from the Shortcut Column model while Figure 8 shows DEETHANIZER column monitor sheet. Ethane recovery at the top of the column is $99 \%$ of the amount of ethane feed to the DE-ETHANIZER column. 


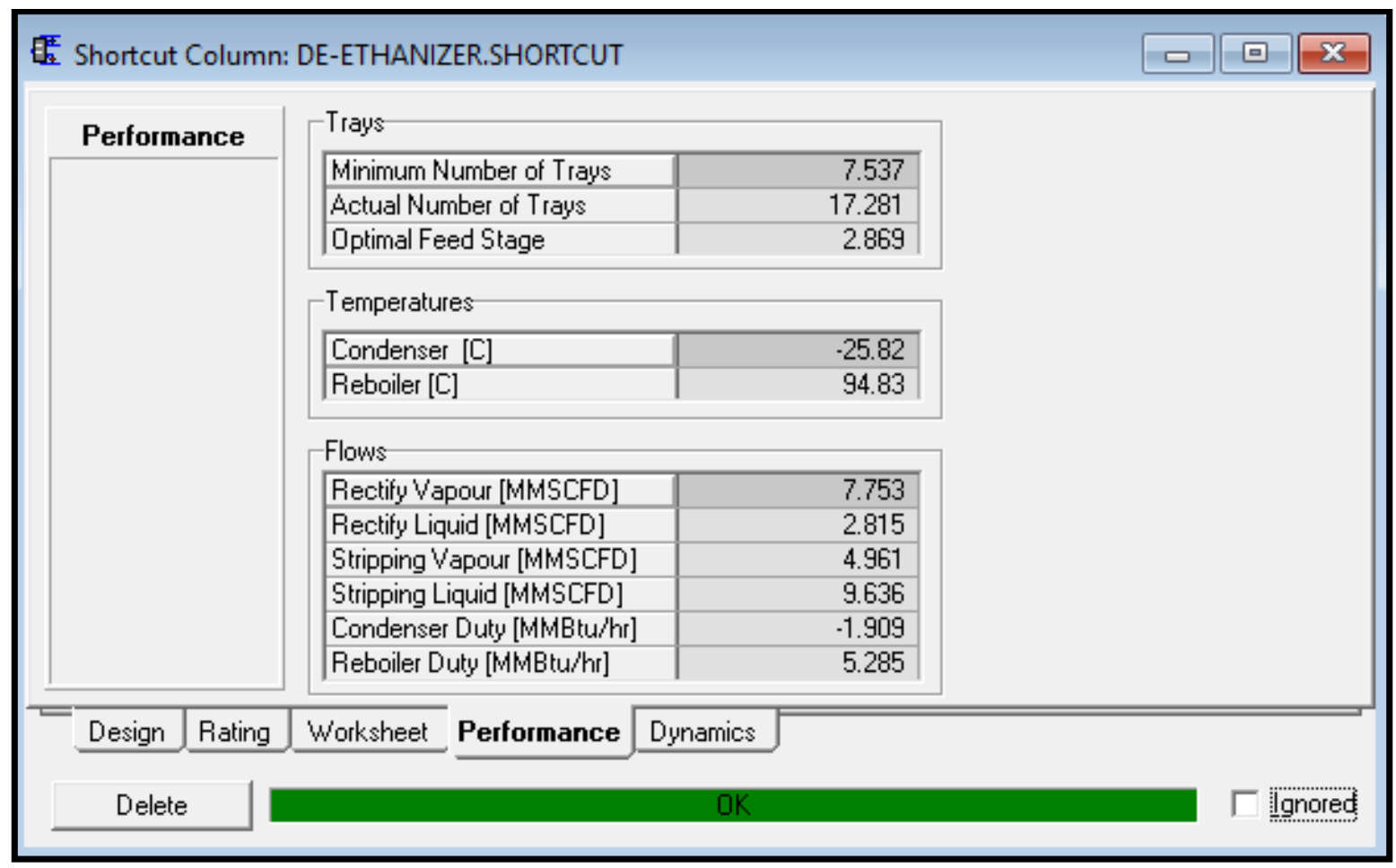

Figures 7. Performance of DEETHANZIER tower from the Shortcut column model.

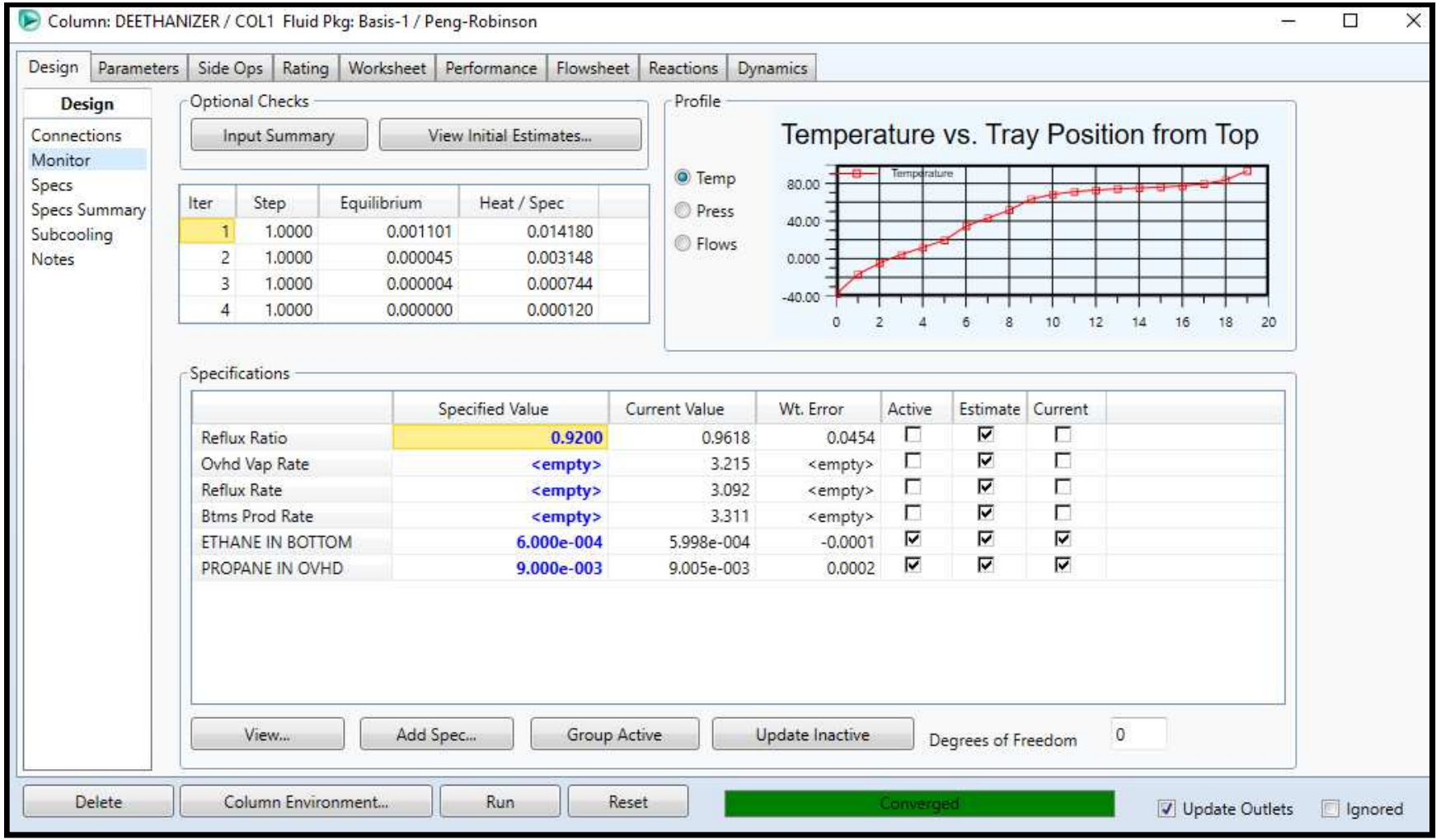

Figures 8. DE-ETHANIZER system monitor sheet.

\subsubsection{DE-BUTANIZER System Setting up}

By setting I-BUTANE as the light component in bottom product and its mole fraction in the bottom product is $(0.001)$, the performance of the proposed column can be achieved by using the Shortcut Column model in HYSYS. Figure 9 illustrates the number of ideal trays, the optimal feed location, condenser duty and re-boiler duty for the De-Butanizer column obtained from the Shortcut Column model while Figure 10 shows De-Butanizer column monitor sheet. 


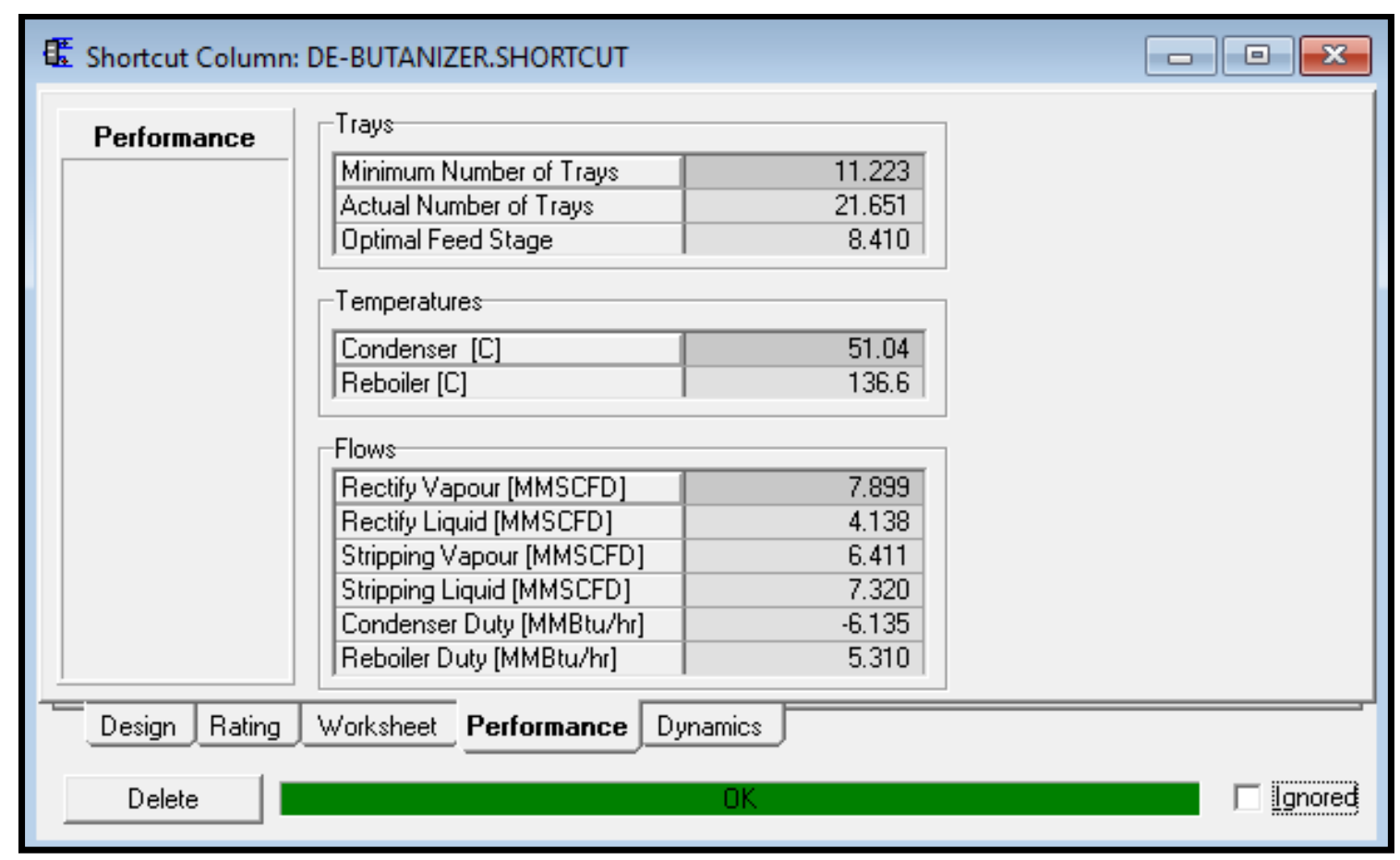

Figures 9. Performance of DE-BUTANIZER tower.

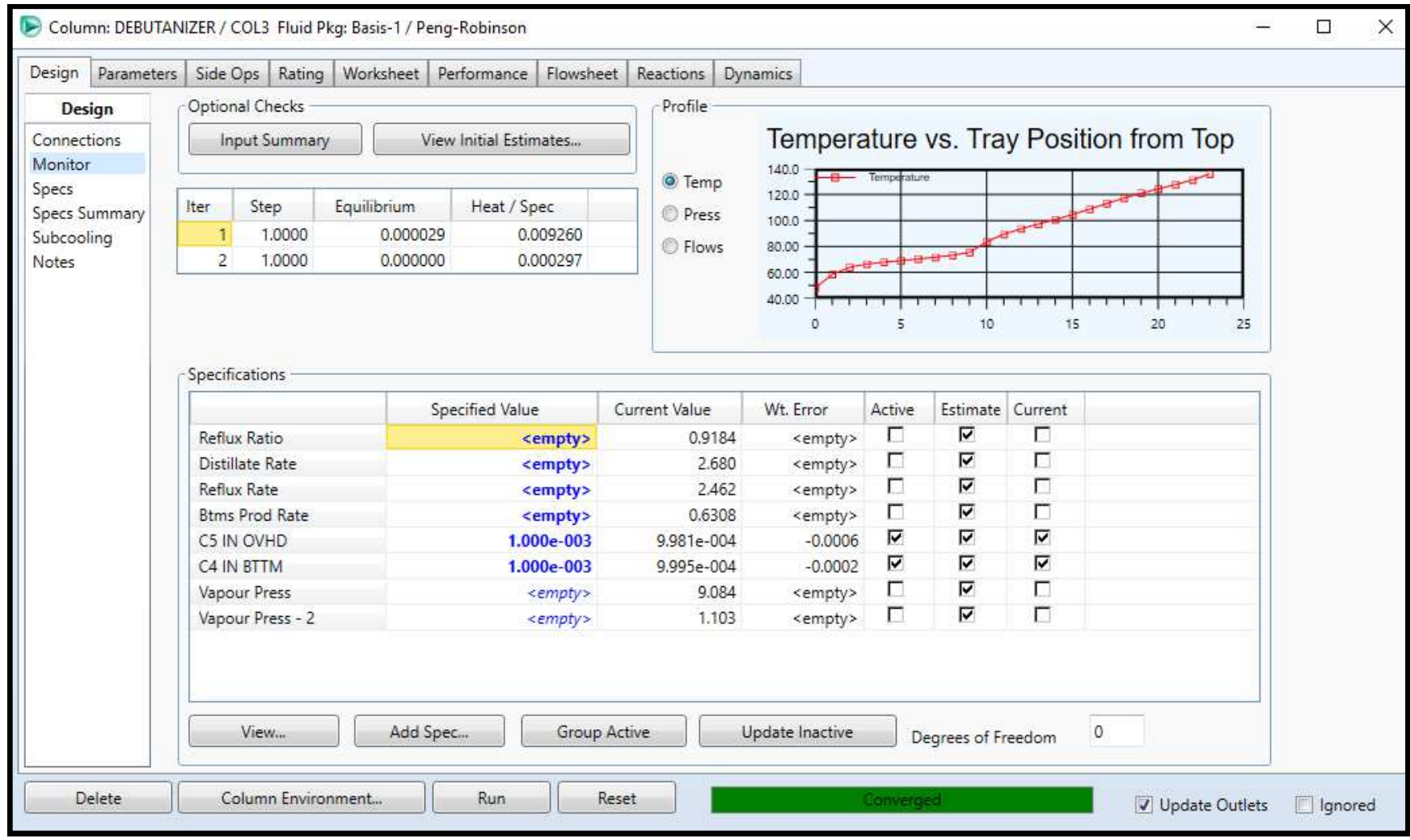

Figure 10. DE-BUTANIZER system monitor sheet.

After completion of DE-BUTANIZER system data, the new retrofitted plant steady state model, Figure 11, was run.

\section{Results and Discussions}

The following products production rates and specifications will be obtained by modeling the new retrofitted plant (Table 3 , 4 and 5). 
Table 3. Stabilized Condensate Specifications obtained from simulation results.

\begin{tabular}{ll}
\hline Condensate property & Value \\
\hline Production Rate, BBLs/Day & 513 \\
REID Vapor Pressure (RVP), psia & 9 \\
Specific Gravity & 0.6347 \\
\hline
\end{tabular}

Table 4. Sales Gas Specifications obtained from simulation results.

\begin{tabular}{ll}
\hline Component or Gas Property & Value \\
\hline Flow Rate, MMSCFD & 54.92 \\
Gross Calorific Value, BTU/SCF & 1093 \\
Water Dew Point, ${ }^{\circ} \mathrm{C}$ & -30 at $82 \mathrm{Kg} / \mathrm{cm}^{2}$ \\
Hydrocarbon Dew Point, ${ }^{\circ} \mathrm{C}$ & -5 at $82 \mathrm{Kg} / \mathrm{cm}^{2}$ \\
Carbon Dioxide, mol\% & 1.0 \\
Hydrogen Sulphide, ppm & 1.0 \\
Oxygen, mol\% & Less than 0.0005 \\
Pressure & The operating design delivery pressure at the battery limit is $82 \mathrm{Kg} / \mathrm{cm}^{2}$ \\
\hline
\end{tabular}

Table 5. LPG Specifications obtained from simulation results.

\begin{tabular}{ll}
\hline LPG Property & Value \\
\hline Production Rate, Ton/Day & 87 \\
$\mathrm{C} 2, \mathrm{~mol} \%$ & 0.04 \\
$\mathrm{C} 5, \mathrm{~mol} \%$ & 0.60 \\
Vapor Pressure, Kg/cm ${ }^{2}$ & $9.1 @ 50^{\circ} \mathrm{C}$ \\
Relative Density & $0.5394 @ 60 / 60 \mathrm{~F}$ \\
Hydrogen Sulphide, ppm & 1.0 \\
Total Calorific Value, BTU/SCF & 2826 \\
\hline
\end{tabular}

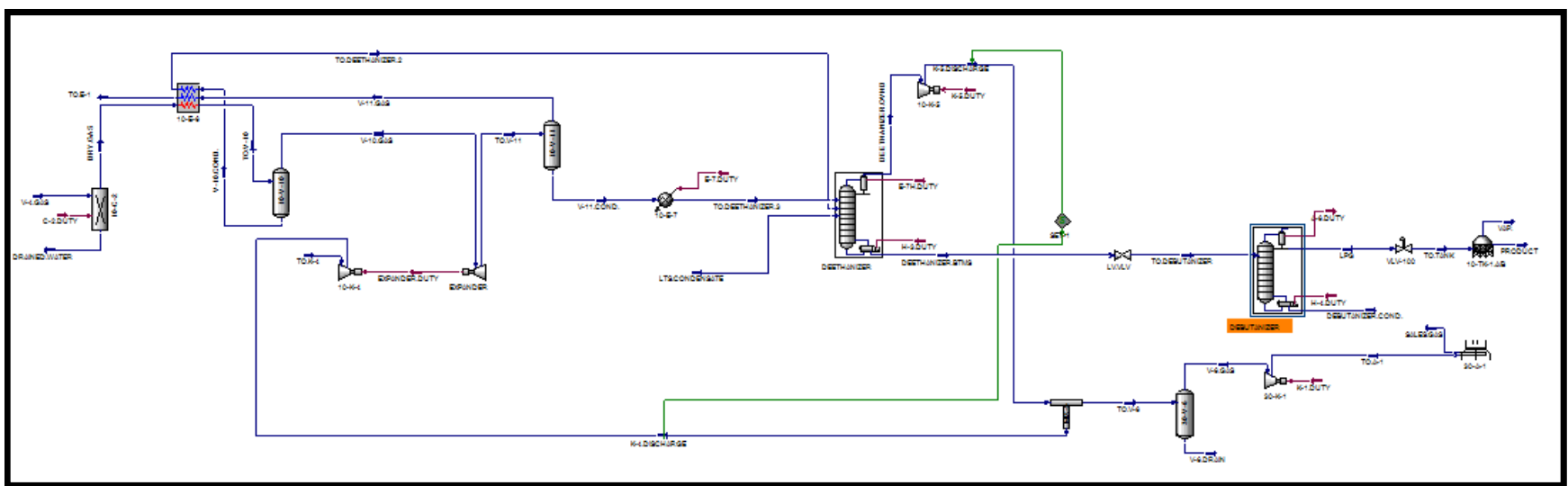

Figure 11. Process flow diagram for the new LPG recovery unit.

\section{Economic Evaluation}

Economic evaluation for the Retrofitted Plant is conducted by using Aspen Capital Cost Estimator V8.8. The economic evaluation module develops both total capital and operating costs. The following steps have been considered for the development of the economic evaluation module.

\subsection{Total Capital Investment Estimation}

The capital for designing and building the plant ready for start-up and include:

\subsubsection{Fixed Capital Investment (FCI)}

a. Total direct costs are $\$ 7,484,027$.

b. Total indirect costs are $\$ 4,544,038$.

So, total estimated (FCI) for the Retrofitted Plant is $\$ 12,028,065$.

\subsubsection{Working Capital Investment (WCI)}

WCI is the working funds necessary to conduct a day-day business of the firm. These funds are necessary to pay wages and salaries, purchase raw materials, supplies; etc. WCI for the Retrofitted Plant obtained from Aspen Capital Cost Estimator is $\$ 2,161,173$.

\subsubsection{Startup Capital Cost}

When a process is brought on stream, there are certain one-time expenses related to this activity. Startup Capital Cost obtained from Aspen Capital Cost Estimator is $\$ 1,202,807$.

So, the Total Estimated Capital Investment (TCI) is $\$ 15,392,045$.

\subsection{Total Operating Costs}

Operating costs in this paper will consist of maintenance 
expense of the Processing Plant as well as the selling and distribution of produced products, this part represents direct expenses, where the in direct expenses include depreciation of exist assets in the Processing Plant. The operating costs for the Retrofitted Plant obtained from Aspen Capital Cost Estimator are $\$ 5,681,073$.

\subsection{Total Revenues Estimation}

The total sales revenues will be estimated according to the current products sales cost by using Aspen Capital Cost Estimator. Table 6 summarizes all products sales revenues.

Table 6. Daily products sales revenue for the retrofitted plant.

\begin{tabular}{lllll}
\hline Products & Quantity & Unit & Selling price, \$/unit & Total sales price, $\$$ \\
\hline Sales gas & 60,028 & MMBTU & 2.65 & 159,073 \\
Condensate & 513 & BBLs & 80 & 41,040 \\
LPG & 87 & Ton & 800 & 69,600 \\
Total sales price, $\$$ & & & & 269,713 \\
\hline
\end{tabular}

1) So, the excess in revenues due to the proposed modification are $\$ 17,471,880$.

\subsection{Profit Calculation}

Excess Profit before depreciation $=$ Excess in sales revenues - Operating cost

$$
=17,471,880-5,681,073=\$ 11,790,807 .
$$

Total purchased equipment cost (PEC) is $\$ 5,285,887$ after " $n$ " years the salvage value becomes $V_{s}=V_{i}(1-f) n$.

Where: $\mathrm{F}$ is the depreciation factor, $\mathrm{f}=0.2$.

So, the value for the process equipment after one year $=5,285,887 *(1-0.2)=\$ 4,228,710$.

Using straight-line method, $\mathrm{D}($ Depreciation cost $)=\left(\mathrm{V}_{\mathrm{i}}-\mathrm{V}_{\mathrm{s}}\right) / \mathrm{n}$.

Depreciation cost for process equipment after one year $=5,285,887-4,228,710$

$$
=\$ 1,057,177 \text {. }
$$

Excess Gross Profit $=$ Gross profit before depreciation - Depreciation cost

$$
=11,790,807-1,057,177=\$ \mathbf{1 0 , 7 3 3 , 6 3 0} .
$$

2) Assuming local taxes of $30 \%$ so, the Annual Net Profit after taxes $=\$ 7,513,541$.

$$
\begin{aligned}
& \text { Return on Investment }(\mathrm{ROI})=\frac{\text { Net Profit after taxes }}{\text { Total capital investment }}=\frac{7,513,541}{15,392,045}=48.81 \% . \\
& \text { The payback period }=\frac{1}{\mathrm{ROI}}=\frac{1}{0.4881}=2 \text { Years. }
\end{aligned}
$$

\section{Conclusions}

In oil and gas industry, the simulation of natural gas plants is an important issue. It is necessary to establish the model that best represents currently operated gas plants or the new plants proposed for new expansions and for adding new valuable products to the market. Thus, this research work aims to produce LPG from ABU-SANNAN Condensate Recovery plant located in Egypt to increase the production of valuable NGLs. This can be done by the addition of Molecular Sieve based dehydration unit, Turbo-Expander unit, Cold Box heat exchanger, DE-ETHANIZER system, DE-ETHANIZER Overhead compressor, DE-BUTANIZER system, and two LPG storage bullets.

Aspen HYSYS simulation software is used to evaluate process of retrofitting the existing plant to produce LPG. New models are built to be used in bottlenecking the existing process equipment and for rating the new process equipment needed for the new Retrofitted plant. Economic analysis has been carried out to determine the performance and profitability of the plant after retrofitting.

From this research it can be concluded that:

a. Simulation models can be used as a design tool to simulate any assumed process flow sheet or any process retrofit.

b. The created simulation models could be used to model other NGL or LPG plants and they could be used in monitoring and evaluating the performance and productivity of the existing condensate recovery plant and the new retrofitted plant.

c. The developed steady state model can be used as diagnostic tool in the LPG recovery process operations trouble shooting, as it allows testing of the effect of any change in the process and examination of the process malfunction.

d. A comparison of the existing plant before and after plant retrofitting is made using the simulation package of HYSYS V8.8. The results indicate that the retrofitted plant can produce 87 Tons/Day of LPG. 
e. As a result, the gross profit of the retrofitted plant is $\$ 87,731,597$ compared to the gross profit of the currently gas plant is $\$ 75,940,790$.

f. According to the calculations done in this research, the payback period should be within two years which is considered very high. Such payback period illustrates that the mentioned modifications are valuable and profitable to the existing plant.

\section{References}

[1] Mokhatab, Saeid, and William A. Poe. "Handbook of natural gas transmission and processing." Gulf professional publishing, 2012.

[2] Speight, James G. "Natural gas: a basic handbook." Elsevier, 2007.

[3] Richards, G. A., et al. "Issues for low-emission, fuel-flexible power systems." Progress in Energy and Combustion Science 27.2 (2001): 141-169.

[4] Gary, James H., Glenn E. Handwerk, and Mark J. Kaiser. "Petroleum refining: technology and economics." CRC press, 2007.

[5] Kidnay, Arthur J., William R. Parrish, and Daniel G. McCartney. "Fundamentals of natural gas processing. Vol. 218." CRC Press, 2011.

[6] Turton, Richard, et al. "Analysis, synthesis and design of chemical processes." Pearson Education, 2008.

[7] Ahmed, Musab Mukhtar. "Recovery Of Natural Gas Liquids And Produce Liquified Petroleum Gas From Assosiated Natral Gas. Diss." Sudan University of Science \& Technology, 2016.

[8] Ikoku, Chi U. "Natural Gas Production Engineering", Krieger publishing company, Malabar, Florida, 1992.
[9] Mondal, Sukanta Kumar, M. Rakib Uddin, and A. K. Azad. "Simulation and optimization of natural gas processing plant." International conference on mechanical, industrial and materials engineering, Bangladesh. 2013.

[10] Chowdhury, Niaz Bahar, Zahid Hasan, and A. H. M. Biplob. "HYSYS Simulation of a Sulfuric Acid Plant and Optimization Approach of Annual Profit." Journal of Science (JOS) 2.4 (2012).

[11] Lynch, J. T., J. P. McCann, and P. Carmody. "Retrofit of the Amerada Hess sea Robin plant for very high ethane recovery." 84th Annual Convention of Gas Processors Association, San Antonio, TX. 2005.

[12] Lynch, J. T., et al. "Process retrofits maximize the value of existing NGL and LPG recovery plants." 82nd Annual Convention of the Gas Processors Association, San Antonio, TX. 2003.

[13] Mehrpooya, Mehdi, Farhad Gharagheizi, and Ali Vatani. "An optimization of capital and operating alternatives in a NGL recovery unit." Chemical engineering \& technology 29.12 (2006): 1469-1480

[14] Mohamed, Mohamed Shaaban Khater. "An optimization of gas condensate extraction from Abu Sannan fields using optimal process operating conditions." CU Theses (2012).

[15] Peters, Max Stone, et al. "Plant design and economics for chemical engineers. Vol. 4." New York: McGraw-Hill, 1968.

[16] ENPPI. "Abu Sannan Condensate Recovery Plant Operation and Maintenance commissioning protocol." Egypt (1990).

[17] Bhran, Ahmed Abd El-Kader, Mohamed Hassan Hassanean, and Mohamed Galal Helal. "Maximization of natural gas liquids production from an existing gas plant." Egyptian Journal of Petroleum 25.3 (2016): 333-341. 